\title{
COMPORT AMENTO GEOQUÍMICO DOS ELEMENTOS TERRAS RARAS DURANTE PROCESSOS DEALTERAÇÃO HIDROTERMAL: CASO DO MACIÇO GRANÍTICO DA SERRA BRANCA - GOIÁS
}

\author{
RARE-EARTHELEMENTSMOBILITYDURING HYDROTHERMAL \\ ALTERATION: THE EXAMPLE OF THE SERRABRANCA GRANITE - \\ CENTRALBRAZIL
}

\author{
Cristina V. Pinto-Coelho ${ }^{1}$
}

\begin{abstract}
RESUMO
O Maciço Granítico da Serra Branca (MGSB), localizado na Província Estanífera de Goiás e com idade Proterozóico Médio, foi afetado no seu conjunto por alterações hidrotermais pós-magmáticas, em que a principal é a greisenização, com intensidade crescente de W para E. A alteração hidrotermal modificou intensamente a mineralogia e o quimismo dessas rochas. Não obstante, a circulação de fluidos favoreceu apenas a diluição do estoque inicial de terras raras nas rochas magmáticas, sem acarretar fracionamento importante, conforme sugerido pela semelhança entre os espectros normalizados em todas as rochas, a partir do granito menos transformado até o greisen com muscovita e topázio.
\end{abstract}

Palavras-chave: elementos terras raras, alteração hidrotermal, granito, greisen, Brasil, Goiás.

\section{EXTENDED ABSTRACT}

Among the Goiás Tin Province batholiths, the Serra Branca Granite (SBG) is characterized by the high level and the wide extension of post-magmatic metasomatic and hydrotermal processes, chiefly greisenization related to $\mathrm{Sn}$-concentrations. The following discussion is about the REE behaviour during these processes, and the evaluation of relative contribution of magmatic and hydrothermal sources for REE concentrations. The similarities between all the chondrite-normalized REE patterns within the SBG rocks, the less altered granites as well as the most completely transformed rocks (greisens and micaceous veins), support the hypothesis of a unique magmatic signature, the effect of greisen-forming fluid circulation being restricted to a simple dilution of the initial REE stock, without important partitioning.

1 Universidade Federal do Paraná - UFPR. Departamento de geologia - DEGEOL. Centro Politécnico, $\mathrm{s} / \mathrm{n}^{\circ}$ - Jardim das Américas, Caixa Postal 19.001- CEP 81.531-990 - Curitiba - PR - Brasil cristinavpc@ufpr.br 
PINTO-COELHO, C. V. Comportamento geoquímico dos elementos terras raras...

All the REE patterns for separated minerals (micas, fluorite, cassiterite) show similarities with the REE profils in the SBG rocks. The behaviour of this elements seems to be consistent with a first stage of primary concentration during the magmatic differentiation, and a later stage of partial leaching related to post-magmatic transformations (especially greisenization) due to important fluid circulations. So, these fluids probably did not transport significant REE amounts from a distant unknown source, but they more likely mobilized part of the REE stock previously concentrated in the granitic rocks.

The REE patterns support the affinity of the SBG with A-type granites and they can be compared to REE profiles in other tin-granites from the Province of Goiás and from Alaska.

Key-words: rare earth elements, hydrothermal alteration, granite, greisen, Brazil.

\section{INTRODUÇÃO}

O Maciço Granítico da Serra Branca (MGSB) localiza-se no extremo Norte do Estado de Goiás, a aproximadamente $600 \mathrm{Km}$ de Brasília e a $22 \mathrm{Km}$ a SE do distrito de Minaçu; limita-se pelos paralelos $13^{\circ} 33^{\prime} 45^{\prime \prime}$ e $13^{\circ} 38^{\prime} 50^{\prime \prime}$ de latitude $S$ e pelos meridianos $48^{\circ} 07^{\prime} 13^{\prime \prime}$ e $48^{\circ} 05^{\prime} 34^{\prime \prime}$ de longitude W.

O MGSB situa-se na sub-província Tocantins da Província Estanífera de Goiás, (Marini \& Botelho 1986). $\mathrm{O}$ interesse econômico do maciço residiu, durante alguns anos, na cassiterita associada aos greisens, descoberta em 1972, e explorada até o início da década de 80. A partir daí, com a queda do preço do estanho no mercado internacional, o interesse voltou-se para o berilo e para a mica dos greisens, explorados de maneira artesanal, e logo abandonados (Andrade 1978). Os granitos da Província Estanífera, alojados no embasamento do Cinturão Brasília, têm idades do Proterozóico Médio e assemelham-se, quimicamente, a granitos do tipo A (Marini \& Botelho 1986, Botelho 1992).

Com objetivo de esclarecer o comportamento dos elementos terras raras - ETR durante os processos de alteração hidrotermal que atingiram o MGSB foram analisadas por ICP-MS no Centre de Recherches Pétrographiques et Géochimiques - C.R.P.G. (França), após fusão com $\mathrm{LiBO}_{2}$ e dissolução por $\mathrm{HNO}_{3}, 25$ amostras de rocha total (granitos, greisens e filões micáceos), 16 amostras de micas separadas (muscovita e biotita) e 4 amostras de cassiterita. Quatro amostras de fluorita foram analisadas por ativação neutrônica (Laboratório P. Sue - França).

\section{O MACIÇO GRANÍTICO DA SERRA BRANCA QUADRO ESTRUTURAL GERAL}

O MGSB forma uma estrutura elíptica, com eixo maior $\mathrm{N} 15^{\circ} \mathrm{W}$, dominada por quartzitos encaixantes subhorizontais do Grupo Araí, com idade do Proterozóico Médio, possivelmente posteriores à mise en place do plúton (figura 1). O maciço granítico encontra-se fortemente estruturado, adquirindo, na parte $\mathrm{E}$, uma xistosidade plana sub-horizontal. Os quartzitos exibem altitudes mais elevadas nas bordas Sul e Leste; o contato ocidental é balizado, de maneira regular, por xistos da Formação Ticunzal do Grupo Serra da Mesa.

$\mathrm{O}$ fraturamento, com características anisótropas, apresenta direção ENE na parte ocidental do MGSB e NNE na sua porção oriental. Duas falhas maiores submeridianas interrompem os quartzitos na porção Sul. As falhas afetam indistintamente granitos, greisens e quartzitos, mas as estruturas maiores afetam essencialmente o plúton, sem se prolongar na auréola quartzítica. Não foi observada nos quartzitos xistosidade planar sub-horizontal semelhante àquela encontrada nos granitos da fácies oriental do maciço. Nestes quartzitos foi notada a presença de estruturas sedimentares (estratificação oblíqua). Nenhum filão, ou apófise, foi encontrado recortando a seqüência de quartzitos.

\section{PETROGRAFIA DAS FÁCIES GRANÍTICAS}

O exame macroscópico das rochas amostradas revela a existência de variações petrográficas importantes no MGSB, levando à definição de quatro tipos petrográficos distintos (figura 1): a) biotita-granito porfirítico heterogranular, com granulação grossa; b) granito com duas micas, heterogranular, com granulação grossa; c) muscovita-granito, heterogranular e granulação grossa e d) muscovita-topázio granito, descrito somente na porção oriental do maciço. Ocorrem, ainda a Leste do maciço, greisens apicais e filões micáceos. As fácies à duas micas e à muscovita-topázio não são cartografáveis na escala aqui adotada.

As modas situam-se, preferencialmente, no domínio 3 do diagrama QAP (Streckeisen 1976), correspondendo aos granitos s. $s(3 \mathrm{a}=$ sienogranitos; $3 \mathrm{~b}=$ monzogranitos) (Pinto-Coelho 1996). No caso do biotita-granito há grande dispersão dos pontos amostrados, podendo ser atribuída seja à heterogeneidade textural, seja às condições genéticas (variação textural resultante de perdas parciais de uma fase vapor, segundo Newberry et al. 1990).

O biotita-granito porfirítico grosso encontrase fortemente estruturado, com desenvolvimento de 


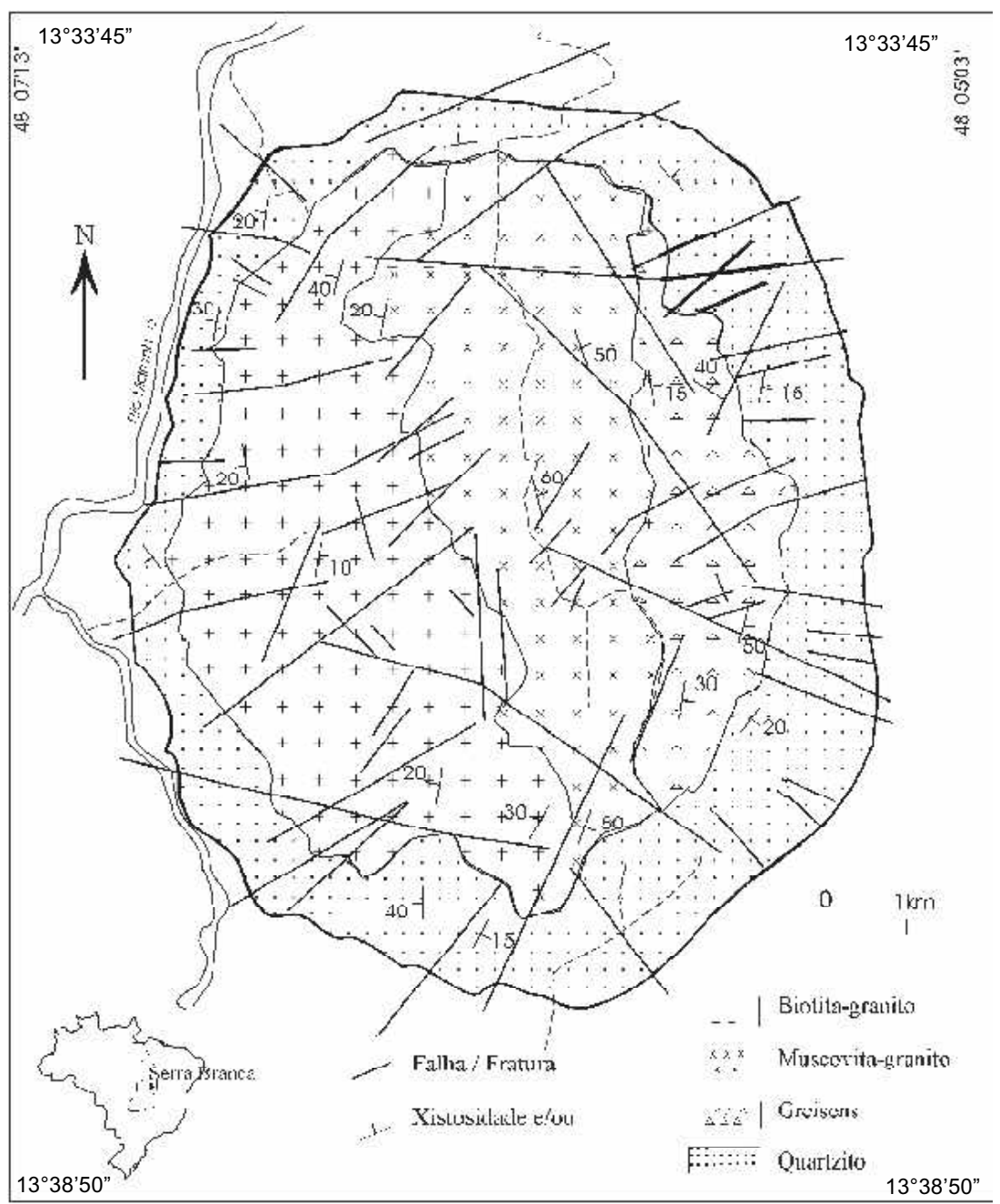

Figura 1- Carta geológica esquemática do Maciço Granítico da Serra Branca e encaixantes (modificada de Andrade 1978). Geological sketch map of the SBGM and surrounding rocks. 
foliação com direção NW, aflorando na porção ocidental do maciço. Compõe-se essencialmente por quartzo, biotita, muscovita, feldspato potássico e albita.

O granito porfiritico com duas micas exibe características petrográficas semelhantes às do biotitagranito, exceto no que se refere aos aumentos da deformação e das proporções modais de quartzo, de muscovita, de fluorita, de microclínio tardio e fases minerais acessórias radioativas e a elementos terras raras. Encontram-se, nesta fácies, cristais reliquiares de almandina e de plagioclásio de composição $\mathrm{An}_{20-23}$ (Pinto-Coelho 1996).

O muscovita-granito heterogranular aflora na porção oriental do maciço. É a fácies mais evoluída do MGSB, composta por quartzo, albita, microclínio pertítico e muscovita, com as proporções modais desta última sendo nitidamente superiores às das demais fácies.

$\mathrm{Na}$ porção oriental do maciço encontra-se o muscovita-topázio granito, com características petrográficas semelhantes ao muscovita-granito heterogranular. Os minerais acessórios e secundários mais freqüentes nesta fácies são zircão, apatita, allanita, fluorita, monazita, óxidos/hidróxidos de ferro e opacos. O contato observado entre o biotita-granito e o muscovita-granito é tectônico.

Importantes variações observadas na composição modal dos granitos do MGSB resultaram da atuação de fenômenos pós-magmáticos: albitização, greisenização - a mais desenvolvida - e microclinização. A greisenização oblitera inteiramente a textura da rocha original e é responsável pela formação de greisens maciços observados na porção oriental do MGSB.

Filões micáceos orientados $\mathrm{N}$ a $\mathrm{N} 15-30^{\circ} \mathrm{W}$ associam-se, preferencialmente, ao muscovita-granito e aos greisens. Compõem-se de $95 \%$ de mica com granulação fina à muita fina e coloração esverdeada característica, de composição predominantemente fengítica. Os minerais acessórios são topázio, zircão, apatita, opacos e, mais raramente, epidoto e fenacita. Estes filões, assim como os greisens, são afetados por foliação sub-horizontal ou levemente inclinada para $\mathrm{E}$.

Em nenhuma destas fácies foi identificada a presença de muscovita primária (magmática), conforme critérios texturais estabelecidos por Miller et al. (1981), Speer (1984), Bailey (1984) e Borodina \& Fershtater (1988). Independentemente do hábito, origem ou disposição textural, esta mica apresenta caráter fengítico acentuado, sendo empobrecida em $\mathrm{Mg}$, $\mathrm{Ti}$, Na e Li (Pinto-Coelho 1996); não foram observadas variações importantes na composição química da mica branca de granitos, greisens ou mesmo filões micáceos.

\section{PETROGRAFIA DOS GREISENS}

A área de ocorrência dos greisens da parte oriental do MGSB não pôde ser delimitada em função da intensa exploração mineral artesanal desenvolvida na região durante vários anos. $\mathrm{O}$ solo é inteiramente coberto por fragmentos de quartzo oriundos dos diversos veios que cortam as fácies graníticas e greisens do maciço.

A cor dos greisens é extremamente variável em função das espécies minerais predominantes: amarelo-esverdeado e amarelado quando predominam quartzo e mica branca; amarelo esverdeado pálido quando minerais de cobre estão presentes; castanho-amarelado se minerais de ferro associam-se aos de cobre, e nuances variadas de cinza e marrom quando a cassiterita está presente. Esse acessório encontra-se disseminado ou sob a forma de agregados pluricentimétricos. A textura dos greisens é equi a heterogranular fina à média $(2-7 \mathrm{~mm})$ com freqüentes agregados quartzosos pluricentimétricos, provavelmente veios $\mathrm{e}$ exsudatos.

A mineralogia dos greisens é dominada pela associação quartzo - mica branca. São reconhecidas várias gerações de cada uma dessas fases minerais, evidenciando, assim, a importância da recristalização que oblitera a textura da rocha inicial. Apesar da intensidade da estruturação macroscópica, o quartzo, tanto aquele disposto intersticialmente, quanto aquele em agregados policristalinos, exibe deformação moderada, denotando a amplitude da recristalização. As fraturas estão habitualmente preenchidas por mica branca ( \pm clorita).

A mica branca é igualmente heterogênea e apresenta-se em diversas gerações: em placas com dimensões medianas, por vezes deformadas e marcando uma xistosidade grosseira ou em forma de agregados de diminutas palhetas imersos na mesóstase. Freqüentemente ocorre, ainda, sob forma de inclusões em topázio e fluorita; uma geração tardia cimenta cristais de cassiterita.

Feldspato da rocha inicial raramente é conservado nos greisens, sob forma de relictos de albita, comumente inclusos em quartzo e cuja composição é idêntica à do plagioclásio do muscovita-granito (PintoCoelho 1996). O feldspato potássico neoformado é abundante, conduzindo Andrade (1978) a individualizar uma fácies de greisens feldspatizados. Microclínio não pertítico, com geminação em grade bem desenvolvida, em indivíduos xenomórficos límpidos, é visivelmente posterior à deformação geral. Com cristalização tardia, esse mineral apresenta composição comparável àquela do microclínio identificado nas diferentes fácies graníticas do MGSB. O processo de microclinização é, 
assim, um fenômeno de alteração pós-greisen, desenvolvido de maneira intensa, levando, por vezes, à formação de bolsões monominerálicos.

Topázio e fluorita são freqüentes nos greisens. Outros minerais acessórios e acidentais incluem cassiterita, monazita, scheelita, grafita, esfalerita, zoisita, zircão, apatita, clorita, opacos (sobretudo minerais de $\mathrm{Cu}$ e $\mathrm{Fe}$ ) e, raramente, biotita.

\section{GEOQUÍMICA DAS FÁCIES GRANÍTICAS}

\section{Elementos maiores}

Os granitos do MGSB foram submetidos a importantes alterações hidrotermais, cuja intensidade cresce de $\mathrm{W}$ para $\mathrm{E}$, a partir do biotita-granito, em direção aos greisens orientais. As variações geoquímicas refletem, conseqüentemente, tais processos tardios, mascarando a assinatura magmática original dessas rochas. Não obstante, considera-se como hipótese de trabalho a seguinte sucessão faciológica, comum em um processo de diferenciação (cf. Vanshteyn et al. 1979): biotitagranito $\Rightarrow$ granito com duas micas $\Rightarrow$ muscovita-granito $\Rightarrow$ muscovita-topázio granito.

Globalmente, os granitos do MGSB são silicosos $\left(\mathrm{SiO}_{2} \cong 75 \%\right)$, potássicos $\left(\mathrm{K}_{2} \mathrm{O} \cong 4,8 \%\right)$, fraca a moderadamente sódicos, pouco ferríferos, praticamente desprovidos de óxidos de $\mathrm{Ca}, \mathrm{Mg}$ e $\mathrm{Ti}$ e empobrecidos em
F e Li, e com caráter fortemente peraluminoso (PintoCoelho 1996).

No diagrama A - B de Debon \& Le Fort (1983, 1988), mostrado na figura 2 , essas rochas distribuemse ao longo do domínio I (muscovita ou muscovita > biotita), ressaltando o caráter fortemente peraluminoso (corindon normativo ou muscovita mesonormativa). No diagrama $\mathrm{Q}-\mathrm{P}(\mathrm{Q}=\mathrm{Si} / 3-(\mathrm{K}+\mathrm{Na}+2 \mathrm{Ca} / 3)$ e $\mathrm{P}=\mathrm{K}-$ $(\mathrm{Na}+\mathrm{Ca})$ proposto por Debon \& Le Fort (1988), observa-se um "trend" curvo, correspondendo globalmente à diminuição de $\mathrm{Q}$, correlativamente ao aumento da quantidade de albita (figura 3).

\section{Elementos traço}

A distribuição dos elementos traço é mais sensível e diagnóstica dos processos petrogenéticos, desde a fonte do magma, até as transformações pósmagmáticas, contrariamente aos elementos maiores (Cocherie 1978, Tindle \& Pearce 1981, Pearce et al. 1984, Eby 1990).

A análise da distribuição dos elementos traço nos diferentes granitos do MGSB permite as seguintes constatações sobre o seu comportamento em relação à sílica:

- Elementos que não apresentam correlação com a sílica: As, Be, Cs, Cu, Mo, Pb, Zn e Ta. U e Th têm comportamento aleatório, apesar da razão

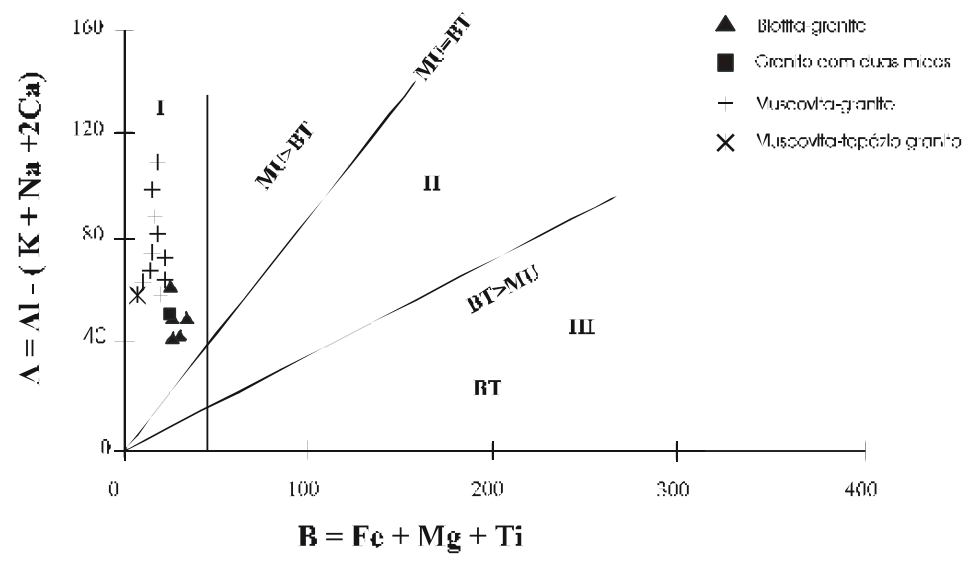

Figura 2 - Gráfico A-B (modificado de Debon \& Le Fort 1983, 1988) para as fácies graníticas do MGSB. I = campo dos leucogranitóides. Graph A - B (modified from Debon \& Le Fort 1983, 1988) for the SBGM granitic facies. $I=$ leucogranitoids field. 


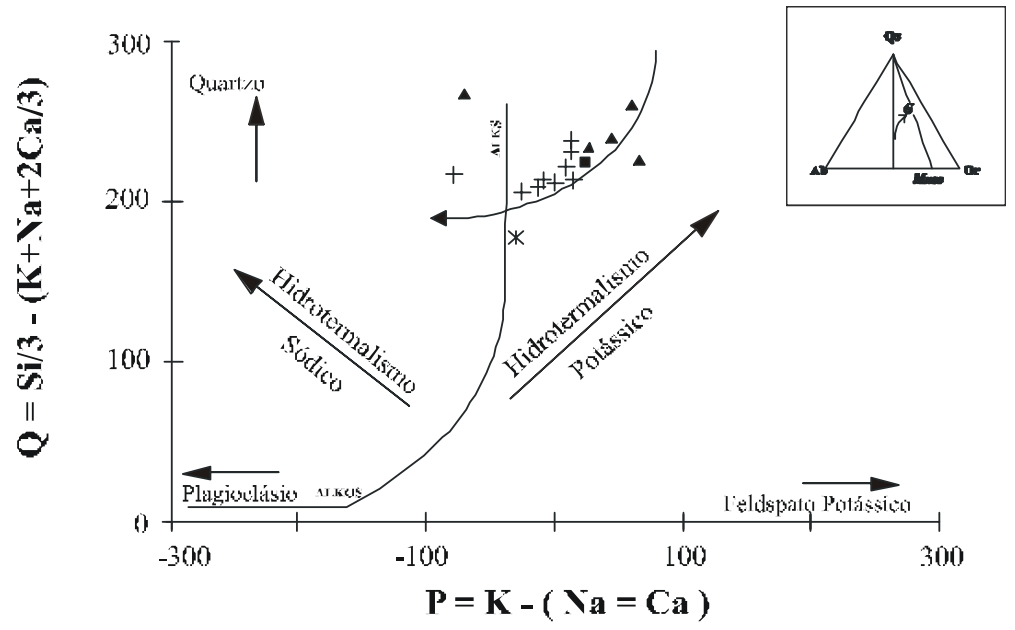

Figura 3 - Diagrama Q - P catiônico modificado de Debon \& Le Fort (1988) para as fácies graniticas do MGSB. Os trends das alterações são aqueles estabelecidos por Bowden et al. (1990) para granitóides anorogênicos da Namíbia. Legenda igual à da Figura 2. ALKS = saturado em álcalis. ALKOS = supersaturado em álcalis. $Q-P$ cationic diagram modified from Debon \& Le Fort (1988) for the SBGM granitic facies. The alterations trends are those established by Bowden et al. (1990) for Namibian anorogenic granitoids. Legends as for Figure 2. ALKS = alkalis saturated. ALKOS = alkalis oversaturated

U/Th ser globalmente mais elevada no muscovita-topázio granito;

- Elementos com correlação linear com a sílica: $\mathrm{Ba}, \mathrm{Rb}, \mathrm{Sr}, \mathrm{Ga}, \mathrm{Nb}, \mathrm{Zr}$ e Hf. Os quatro primeiros são controlados pelas fases mineralógicas principais (feldspatos e micas); os demais, por minerais acessórios;

- Elementos com correlação exponencial com a sílica: F, Li, Sn, W e Sc, ligados, preferencialmente, às alterações pós-magmáticas (albitização, greisenização e microclinização) (Pinto-Coelho 1996).

O teor de Ga é condicionado pelo de sílica, mostrando comportamento semelhante ao do $\mathrm{Al}_{2} \mathrm{O}_{3}$ (PintoCoelho 1996). Elevados teores em Ga caracterizam granitos tipo A (Collins et al. 1982), nos quais alcançam 40 ppm (Walen et al. 1987). Valores encontrados para os granitos do MGSB ( $\cong 55$ ppm para o muscovita-granito) ultrapassam largamente os valores citados na literatura. Os teores elevados em Ga caracterizam os granitos da Província Estanífera de Goiás: 20 a 40 ppm para os granitos da Serra Dourada e Sucuri (Bilal 1991) e 25 a 60 ppm para os granitos da subprovíncia Paraná (Botelho 1992).
A quase totalidade dos elementos traço varia de maneira importante durante o fenômeno de greisenização do MGSB, seja positivamente (introduzidos, como Rb, Ga, Nb, Sn, W, F), seja negativamente (lixiviados, como $\mathrm{Ba}$ e $\mathrm{Sr}$ ). Comportamentos evolutivos semelhantes àqueles encontrados nos granitos e greisens do MGSB foram descritos por Hall (1971), Aleksandrov (1977), Bailey (1977), Charoy (1979), Plimer (1987), Breiter et al. (1991) e Cuney et al. (1994).

\section{Elementos Terras Raras - ETR}

O estudo comparativo do fracionamento dos ETR em cada tipo de rocha ígnea permite obter informações sobre a história geológica, a partir da fonte, da evolução magmática a eventuais transformações ocorridas nas fases subsolidus e deutéricas (hidrotermais s.I.) (Bowden \& Whitley 1974, Koljonen \& Rosenberg 1974, McCarthy \& Kable 1978, Fowler \& Doig 1983, Möller \& Muecke 1984, Michard \& Albarède 1986, Ward et al. 1992). O comportamento dos ETR durante as alterações hidrotermais demonstra que, em geral, as paragêneses acessórias controlam sua distribuição, mas mudanças importantes na forma dos espectros não ocorrem necessariamente (Bowden \& Whitley 1974, Alderton et al. 
PINTO-COELHO, C. V. Comportamento geoquímico dos elementos terras raras...

1980, Baker 1985, Morteani et al. 1986, Cathelineau 1987, Ward et al. 1992). A diminuição de $\Sigma E T R$ da rocha sã para a rocha alterada é a regra geral na maior parte dos casos. As variações nas fases minerais acessórias são importantes para explicar as mudanças no comportamento dos ETR.

As concentrações médias em ETR das amostras analisadas, assim como razões interelementares, encontram-se na tabela 1 .

\section{ETR em rocha total - Fácies graníticas}

As concentrações absolutas no interior de cada grupo petrográfico são essencialmente variáveis. Notase um empobrecimento do total de ETR a partir do biotitagranito ( $2254 \mathrm{ppm})$, granito com duas micas $\sum 182$ ppm), até o muscovita-granito ( $295 \mathrm{ppm})$. Apenas o biotita-granito apresenta o total de ETR próximo à média de 229 ppm estabelecida por Hermann (1978) para granitóides ricos em $\mathrm{SiO}_{2}\left(\mathrm{SiO}_{2}>70 \%\right)$.

Os espectros normalizados aos condritos (Evensen et al. 1978) para fácies graníticas, greisens e micas são mostrados na figura 4. Apesar de forte dispersão no interior de cada grupo petrográfico, o aspecto geral dos espectros é rigorosamente idêntico. Tal fato é particularmente evidente para os ETR leves, que apresentam sistematicamente discreta anomalia negativa em Nd. A dispersão dos "trends" definidos pelos ETR pesados é mais importante. A anomalia negativa em Eu é comum e aumenta em direção ao muscovita-granito (média de $\mathrm{Eu} / \mathrm{Eu}_{\mathrm{N}}=0,090$ para o biotita-granito; 0,105 para o granito com duas micas e 0,039 para o muscovitagranito).

O muscovita-topázio granito é fortemente empobrecido em ETR quando comparado ao muscovita-granito, apresentando, entretanto, um espectro similar (figura 4). Perfil de TR semelhante foi encontrado por Newbery et al. (1990) em granitos estaníferos fortemente diferenciados do Alaska.

O fracionamento dos ETR pesados é mais importante que o dos ETR leves, onde $(\mathrm{La} / \mathrm{Sm})_{\mathrm{N}}=1,73$ (biotita-granito); 1,7 (granito com duas micas); 1,24 (muscovita-granito) e $(\mathrm{Gd} / \mathrm{Yb})_{\mathrm{N}}=5,89$ (biotita-granito); 10,32 (granito com duas micas); 7,55 (muscovita-granito). Por outro lado, o fracionamento entre Gd e Dy é sistematicamente mais fraco em todas as amostras analisadas, traduzindo-se por um espectro plano ou ligeiramente decrescente para ambos os elementos.

Correlações positivas foram encontradas entre $\Sigma$ ETR e $\mathrm{SiO}_{2}, \mathrm{Y}$ e $\mathrm{Zr}$ e entre $\mathrm{Eu}$ e $\mathrm{Ba}$ e $\mathrm{Sr}$; correlação negativa foi observada entre $\mathrm{Eu}$ e $\mathrm{Rb}$ (Pinto-Coelho 1996, Pinto-Coelho et al. 1999, Pinto-Coelho \& Charoy 2001).

\section{ETR em rocha total - Greisens}

As médias das concentrações brutas em ETR são mostradas na tabela 1 e os espectros normalizados na

Tabela 1 - Teores médios em ETR de rochas e fases minerais do MGSB. $n=$ número de análises. Média aritmética (desvio-padrão); *normalização aos condritos; na. $=$ não analisado; Rocha $1=$ biotita granito; $2=$ granito com duas micas; $3=$ moscovita granito $; 4=$ muscovita-topázio granito $;=$ greisens e filöes micáceos; $6=$ biotita do biotita granito; $7=$ muscovita do muscovita granito; 8 muscovita do muscovita topázio granito; $9=$ muscovita dos filões micáceos; $10=$ muscovita dos greisens; $11=$ fluorita; $12=$ cassiterita. REE mean concentrations in rocks and separated minerals from the SBGM. $n=$ number of analyses. biotite from biotitic granite; $7=$ mnscovite from mnscovitic granite; $8=$ mnscovite from muscovitdopaz granite; $9=$ mnscovite from micaceous veio; $10=$ muscovite from greise; $11=$ fluorite; $12=$ cassttente.

\begin{tabular}{|c|c|c|c|c|c|c|c|c|c|c|c|c|}
\hline & $1(n=4)$ & $2(n=1)$ & $3(n=9)$ & $\Delta(H=1)$ & $5(n=8)$ & (1) $(n=1)$ & $7(n=2)$ & $8(n=1)$ & $9(n=4)$ & $10(n=5)$ & $11(n=4)$ & $12(n=4)$ \\
\hline \multicolumn{13}{|l|}{ TEDREs } \\
\hline Li. & $43.12(9.55)$ & 39.7 & :.8.5! (8.06j & 3.3 & $5.22(5.12)$ & 2.66 .7 & 41.i10 (27.25) & 3.4 & 4.4il :7.i1) & $2.30(4.15)$ & $56 \sin (10.46)$ & $\therefore .01(1.17)$ \\
\hline $\mathrm{Cu}$ & a2.2S(24.60) & 72.0 & $4.71(2) .(5)$ & 10.9 & $(1.81)(2.65)$ & 215.2 & $97.30(5) .40)$ & 90 & 10.02 (15.68; & $7.82(8.93)$ & 17.23 (25.44; & $2.56(2.73)$ \\
\hline Nd & $48.0 \mathrm{j}(11.26)$ & 35.6 & $2.699(7.65)$ & 4.3 & 5.02 (6.IS) & $: 14.8$ & 47.55 (31.05) & 3.8 & $5.55,8.22$ & $1.90(1.92)$ & $11.85(11.92)$ & 2.02 (I.j5) \\
\hline Sn & $570+337$ & 125 & $3,47(201)$ & 30 & $2,35(2,46)$ & 36,1 & 8.350124 & 2 & 2,97335 & $0.74(045)$ & $20,48(20,79)$ & $0.5-1063$ \\
\hline$F, 1$ & $0, \angle 6,0.12)$ & $0<?$ & $0.13(0.00)$ & 0.03 & $0,070.05$ & 1.39 & 0.280 .08 & 0 & $0.07: 6.04$ & 0020010 & $0.45 \quad(9.41)$ & 0,011 io 090 \\
\hline Cist & $5.73(.3 .3)$ & 2.77 & $8.93(3.54)$ & 3.34 & $2.66(2.58)$ & 38.17 & $29.951112 / 3$ & 2.07 & $3.1 \quad(2.7 i)$ & I. & 32.72 (28.24) & 0.61 (0.17) \\
\hline T. & ก.. & n.:. & r.s. & r.s. & r.s. & ก ล. & r.a. & $z$ & ח.z.. & n.t. & $7.57: 7.06$ & $1 . \mathrm{a}$ \\
\hline [by & $18.55(1.5 y)$ & 2.19 & 9.63 (2.69) & 3.9 & $2.31(2.51)$ & $44.2 x$ & $23 . \angle 2(1.70)$ & 2.26 & $4.17: 2.42 ;$ & 1.6) (1.5) & ח..亡. & $(1.9 x)(0 x)$ \\
\hline Ho & c.:1. & D.i. & c.il. & c..1. & c.i. & $\pi \approx 1$. & L.: & $\mathrm{HL} \ldots$ & It. & D.i. & 7.7711 & บ. d \\
\hline $\mathrm{L}:$ & $5.73(3.91)$ & 2.11 & $1.64(0.53)$ & 0.69 & $0.51(0.43)$ & 20.39 & $\angle .2 \quad(2.42)$ & 0.37 & $0.800 .44)$ & $0.5(10,45)$ & JL: & $0.22(0.14)$ \\
\hline$T_{r}$ & r.s. & 1..4, & r.i, & $\mathrm{r} . \mathrm{x}_{1}$ & r.x. & 11. & r. & 11.2 & 11. & n,i.i. & $3 \backsim 80$ & $1, \mathbf{1}$ \\
\hline$Y a$ & $3.5(2.38)$ & 1.100 & 0.87 (il. 18$)$ & 0.3 & $0.26(i .22)$ & 1.35 & $.98(1.15)$ & 0.21 & $0.5 x_{1}: 6.25$ & I. il. & 3.6 4.57 & 0.2 (illos) \\
\hline L:1 & 0.39 (0.27) & 0.13 & (o.11: (0.03) & 0.013 & i.05 (i..12) & i. 47 & 0. $9(0 / 2 j)$ & 0.02 & 0.1\%, :G.01; & I.ils (îl. 14 ) & $0.12: 6.5 \mathrm{j}$ & 0.02 (il.t.t) \\
\hline \multicolumn{13}{|c|}{ PARÁMETRDS } \\
\hline TR (pari) & $254(62.6)$ & 152 & $111 ; i 3.5$ & $3 i$ & 31 (3. 3.5 & .572 & 255 (157) & 23 & 32 (10) & 17 (74.6) & $11 i 1 \mid j \dot{y}$ & $7.4(7 . i)$ \\
\hline (Le/Snt) & $1.73(0.15)$ & 1.7 & 1.32 (i.). 15$)$ & 8.3 & $1.46(i) .47)$ & 1.9 & .15 io.g7; & : & $0.62,0.7 \%$ & $1.78(1.83)$ & 0.45 (6.59) & ..25 (0.52) \\
\hline$\left[\mathrm{lid} \mathrm{Yb}^{*}\right)^{*}$ & $5.8 \%(5.93)$ & .6 .32 & $3.21(1.96)$ & $6.2 \mathrm{x}$ & $7.7 \times(2.20)$ & $7.0 \%$ & $8.2(0.25)$ & 7.83 & $4.25: 2.5 ?$ & 3.14 (3). & $10.29(9.57)$ & $2.53(1.17)$ \\
\hline$(\mathrm{L}, \mathrm{Yb}, \%$ & $13.74(12.26)$ & 22.7 & -4.27 i 466$)$ & $5.8 ?$ & $: 2.94(8.78)$ & 2.566 & l3.oL (1.37) & {$[0.71\rangle$} & 4.33 l. 23 & $\mathrm{~J} 8.13(3658)$ & 3.75 (5.43) & $3.22(2.83)$ \\
\hline F.. $F_{1}{ }^{*}$ & $0.0 \%, 7.6 \%$ & 0.1 & $0.04(0.02)$ & 0.03 & $0.16(0.14)$ & 0.1 & 0.05 io. $1 \%$ & i & $0.10: 6.05)$ & (1.13 (i) 11 & D.L.ti $(f, \delta i)$ & 0. $0.6:$ (i) (14) \\
\hline
\end{tabular}


PINTO-COELHO, C. V. Comportamento geoquímico dos elementos terras raras...
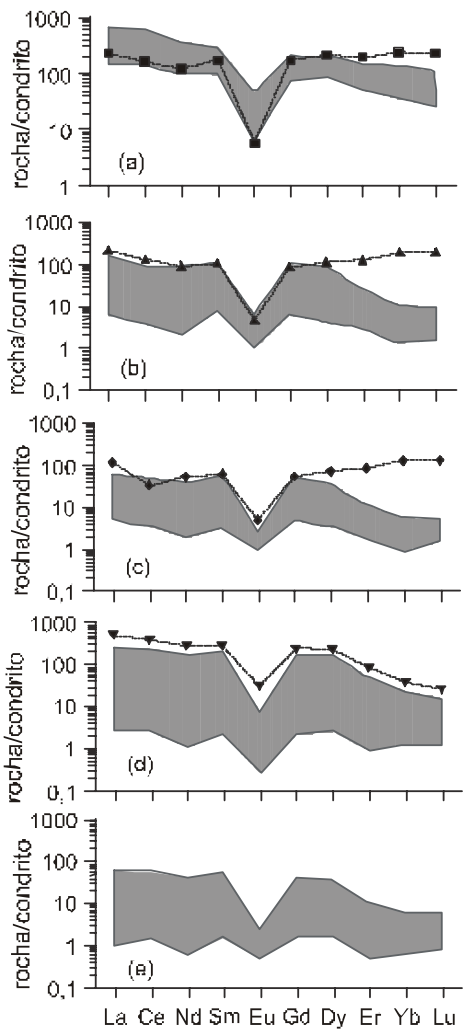

Figura 4 - Espectros de ETR normalizados nas rochas e micas do MGSB. Comparação com o Maciço da Pedra Branca da Província Estanifera de Goiás, segundo Marini e Botelho (1986). (a) Biotita granito e granito com duas micas; quadrados: biotita granito da Pedra Branca. (b) Muscovita granito e muscovita-topázio granito; triângulos: muscovita granito da Pedra Branca. (c) Greisen; losango: greisen associado ao granito da Pedra Branca. (d) Muscovita do muscovita granito e muscovita-topázio granito (campo sombreado) e biotita do biotita granito (triângulos). (e) Muscovita dos greisens e dos filões micáceos. Chondritenormalized REE patterns for SBGM rocks and separated micas (shaded areas). Comparison with the Pedra Branca Massive in the Goiás Tin Province, after Marini and Botelho (1986). (a) Biotitic and two micas granites; square: Pedra Branca biotite granite. (b) Muscovite-topaz granite; triangule: Pedra Branca muscovite granite. (c) Greisen; diamond: greisen associated to the Pedra Branca granite.(d) Muscovite (shaded area) from the muscovite-topaz and biotite (triangule) from the biotitic SBGM granites. (e) Muscovite from greisen and micaceous veins. 
figura 4. A soma dos ETR é baixa, mas o perfil geral dos espectros é bastante semelhante àqueles exibidos pelo muscovita-granito dos quais os greisens derivariam por alteração hidrotermal. A anomalia negativa em Eu tem importância extremamente variável, sendo máxima para amostras de filões micáceos.

Fracionamento importante entre os ETR durante a alteração hidrotermal parece não ter sido significativo (exceção provavelmente para $\mathrm{Eu}$ ), havendo, preferencialmente, diluição variável do estoque inicial nesses elementos (a razão média $(\mathrm{La} / \mathrm{Sm})_{\mathrm{N}}$ para o muscovita-granito é de 12,54 , sendo idêntica à dos greisens, de 13,11).

\section{ETR em fases minerais - Micas}

Os ETR leves, com raio iônico maior, são, preferencialmente, incorporados nos minerais com cátions maiores $(\mathrm{K}, \mathrm{Ba}, \mathrm{Sr})$, enquanto os ETR pesados preferem minerais com cátions menores ( $\mathrm{Mg}, \mathrm{Fe}, \mathrm{Ti}, \mathrm{Mn})$. Balanços geoquímicos de ETR a partir dos teores em diferentes fases minerais são comumente citados na literatura (e.g. Nagasawa \& Schnetzler 1971, Hanson 1978, Alderton et al., 1980, Fourcade 1981, Charoy 1986), mostrando que as fases acessórias são os principais vetores desses elementos (exceção feita ao Eu) em rochas granitóides.

As concentrações médias em ETR de micas das fácies graníticas do MGSB, greisens e filões micáceos são mostradas na tabela 1; espectros normalizados encontram-se na figura 4. Biotita e muscovita exibem espectros com formas semelhantes, e os teores mais elevados são encontrados na primeira. Esses espectros exibem forma semelhante (mesmo fracionamento) àqueles obtidos em rocha total, sobretudo a mica do muscovitagranito e do muscovita-granito com topázio, perfeitamente sobrepostos aos espectros da rocha total.
A mica dos greisens tem baixas concentrações em ETR e espectros mais perturbados, com significativa anomalia negativa em $\mathrm{Nd}$ e Er, além daquela em Eu. Não foi observada diferença entre os perfis apresentados pelas micas dos greisens maciços e dos filões micáceos. Assim, a alteração hidrotermal teria se comportado para os ETR como um processo globalmente diluidor.

\section{ETR em fases minerais - Fluorita}

La e Ce, além do $\mathrm{Y}$, substituem facilmente o Ca na estrutura da fluorita ou formam compostos móveis fluorados de La ou $\mathrm{YF}_{3}$ (Alderton et al. 1980).

As concentrações médias em ETR das fluoritas encontram-se na tabela 1 e os espectros normalizados são mostrados na figura 5 . As amostras SB $-94 \mathrm{~B}$ e SBC-01 correspondem à fluorita violácea dos filões micáceos; SB - 94C é uma fluorita verde clara associada a veio de quartzo alojado em muscovita-granito; SB - 94D é uma fluorita verde escura associada aos greisens. Os teores em ETR leves são extremamente baixos; o fracionamento das ETR pesados é idêntico para todas as amostras. Nota-se que o espectro da amostra SB-94B é idêntico em forma àquele obtido para o muscovita-granito (fase micácea e rocha total), sugerindo precipitação a partir do mesmo fluido (figura 6).

ETR pesados têm tendência a se concentrar em fluoritas cristalizadas em estágios tardios, contrariamente ao que se observa para as ETR leves (Möller et al. 1976, Constantopoulos 1988). Essa característica é presente em todas as amostras de fluoritas analisadas do MGSB (figura 5). No diagrama Tb/La versus $\mathrm{Tb} / \mathrm{Ca}$ (Möller et al. 1976), comumente empregado para caracterizar o tipo genético das fluoritas, as do MGSB estão no domínio hidrotermal (Pinto-Coelho 1996). A anomalia negativa em Eu seria devida à presença de $\mathrm{Eu}^{2+}$,

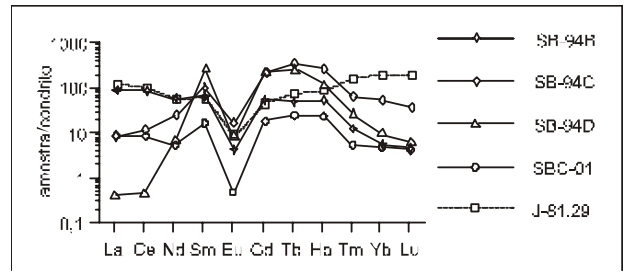

Figura 5 - Espectros de ETR normalizados aos condritos de MGSB. SB-94B e SBC-01: fluorita violácea associada a filão SB-94C: fluorita verde claro em veio de quartzo cortando o muscovita granito; SB-94D: fluorita verde escuro associada a greisen 81.29: fluorita disseminada em calcário no Texas (Rubin et al., 1993). Chondrite-normalized REE patterns for SBGM fluorite. SB-94B and SBC-01: violet fluorite in a micaceous 94C: pale green fluorite in a quartz veinlet cutting the muscovite SB-94D: dark green fluorite in an apical greisen; J-81.29: disseminated in limestone from Texas (Rubin et al., 1993). 


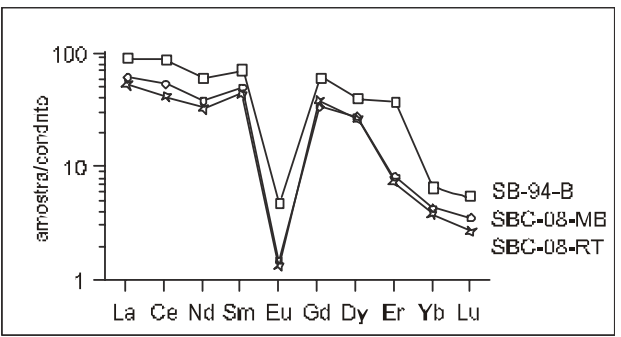

Figura 6 - Filão micáceo associado ao MGSB: comparação entre os aspectos de ETR normalizados aos condritos de fluorita (SB-94B); de muscovita (SBC-08-MB) e de rocha total (SBC-08-RT). Micaceous vein in the SBGM: comparasion between the chondritenormalized REE patterns for separated fluorite (SB-94B) and muscovite (SBC-08-MB), and for the whole rock (SBC-08-RT).

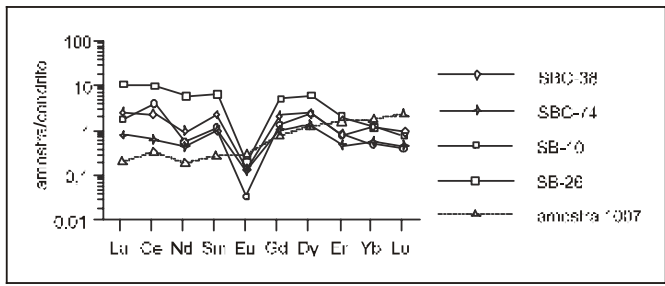

Figura 7 - Espectros de ETR normalizados aos condritos de cassiterita do MGSB. Amostra 1007: cassiterita de greisen associado ao Granito Mole, Austrália (Plimer et al., 1991). Chondrite-normalized REE patterns for SBGM separated cassiterite (4 samples). Sample 1007: cassiterite from a greisen associated to the Mole Granite, Australia (Plimer et al., 1991).

indicando baixa fugacidade de oxigênio (Constantopoulos 1988).

\section{ETR em fases minerais - Cassiterita}

As concentrações médias em ETR das cassiteritas encontram-se na tabela 1 e os perfis normalizados na figura 7. São notávies as baixas concentrações totais em ETR, assim como a semelhança entre as assinaturas nestes elementos.

Plimer et al. (1991) afirmaram que ETR (e demais elementos traço) em cassiteritas refletem a composição dos fluidos a partir dos quais ocorreu a cristalização. Os espectros normalizados das cassiteritas do MGSB são bastante semelhantes àqueles apresentados pelos greisens. Esses, por sua vez, devem a forma dos seus espectros inteiramente à mica. Assim, tal semelhança entre perfis de ETR entre micas, cassiteritas e greisens indicaria a identidade do fluido hidrotermal greisenizante.

\section{DISCUSSÃO E CONCLUSÕES}

O MGSB diferencia-se dos outros maciços graníticos da Província Estanífera de Goiás pela intensidade e extensão dos fenômenos metassomáticos/ hidrotermais pós-magmáticos, particularmente a gresisenização, à qual está relacionada a mineralização em cassiterita. Tais transformações alteraram profundamente, mineralógica e geoquimicamente, as fácies graníticas do maciço.

A semelhança entre os espectros de ETR normalizados aos condritos de todas as rochas do maciço, tanto as fácies magmáticas menos transformadas quanto as fácies hidrotermalizadas (greisens e filões micáceos), testemunha em favor de uma assinatura 
magmática, com simples diluição pelos fluidos responsáveis pela greisenização. A diluição do estoque inicial de ETR, crescente com a intensidade da greisenização, ocorreu sem fracionamento importante, exceção possivelmente feita ao Eu, como mostram os valores das razões $(\mathrm{La} / \mathrm{Sm})_{N},(\mathrm{Gd} / \mathrm{Yb})_{N}$ e $(\mathrm{La} / \mathrm{Yb})_{N}$ nos granitos e nos greisens (tabela 1), assim como o paralelismo dos espectros (figura 4). O empobrecimento mais significativo em ETR é observado entre o biotita-granito $\left(\mathrm{La}_{\mathrm{N}}=480 \mathrm{a}\right.$ $144 \mathrm{ppm})$ e o muscovita granito $\left(\mathrm{La}_{\mathrm{N}}=150 \mathrm{a}<10 \mathrm{ppm}\right)$; nota-se, igualmente, fracionamento dos ETR leves mais fraco no muscovita-granito que no biotita-granito (tabela 1). Entretanto, não se observa variação importante nos espectros apresentados pelos muscovita-granito, greisens e filões micáceos. Nota-se, sobretudo, um aumento na anomalia negativa em Eu, traduzindo maior proporção relativa de mica proporcionalmente a feldspato potássico e plagioclásio, que concentram preferencialmente Eu. Se tal assinatura tivesse sido imposta pelo fluido greisenizante, que teria redistribuído o estoque de ETR nas rochas magmáticas, seria de se esperar um aumento significativo na abundância desses elementos com a intensidade crescente da greisenização. Observa-se o contrário, ou seja, um empobrecimento nas rochas mais muscovitizadas e nos greisens. Tais resultados mostram claramente que a distribuição dos ETR não foi profundamente modificada pela circulação dos fluidos e que a forma dos espectros pode ser utilizada para identificar o protólito original.

A semelhança dos espectros de ETR em minerais separados (mica, fluorita e cassiterita) e em rochas do MGSB é bem ilustrada pela identidade de espectros da fluorita, da mica e da rocha total em amostra de filão micáceo (figura 6). A comparação com dados da literatura mostra que os espectros obtidos sobre fluorita e cassiterita podem apresentar perfis bastante distintos daqueles aqui encontrados (figuras 5 e 7). A forma mimética dos espectros de ETR indicaria filiação entre o mineral e sua rocha-fonte: no caso da fluorita disseminada em calcário no Texas, que mostra perfil de espectro mimético ao do riolito vizinho, ou, ainda, de cassiteritas provenientes de ambientes diversos, depositadas por fluidos portando as características das rochas a partir dos quais são originários ou através dos quais se deu a circulação ou o reequilibrio (Plimer et al. 1991).

No MGSB a alteração hidrotermal comportou-se como um processo globalmente diluidor dos ETR. O mesmo processo ocorreu em outro maciço granítico da
Província de Goiás (maciço da Pedra Branca), onde os teores de ETR decrescem do granito menos evoluído até os greisens (Marini \& Botelho 1986, Botelho 1992, Marini et al. 1992, Teixeira 1998). Halter et al. (1996) obtiveram conclusões semelhantes relativamente à greisenização (greisens com quartzo, topázio e muscovita) do leucogranito de East Kemptville (Nova Escócia).

De modo geral, os ETR são considerados elementos litófilos e preferencialmente imóveis, concentrados, sobretudo, em minerais acessórios (Hanson 1978, Fourcade 1981, Charoy 1986), podendo, entretanto, ser mobilizados por fluidos hidrotermais (Alderton et al. 1980, Fowler \& Doig 1983, Taylor \& Fryer 1983, Morteani et al. 1986, Leroy \& Turpin 1988, Whitford et al.1988, Ward et al. 1992). O exemplo do MGSB mostra-se coerente com esses dois aspectos do comportamento dos ETR citados acima. Os ETR concentraramse inicialmente nas rochas graníticas durante a diferenciação magmática, sendo posteriormente lixiviados durante as transformações pós-magmáticas, implicando, assim, em grande quantidade de fluidos greisenizantes. Tais fluidos não seriam enriquecidos em quantidades notáveis de ETR provenientes de uma fonte distinta e mais afastada, mas teriam herdado parte do estoque original presente nas rochas graníticas através dos quais deu-se a percolação e o equilíbrio.

A forma dos espectros de ETR dos granitos do MGSB e de outros maciços da Província Estanífera de Goiás (Marini \& Botelho 1986, Botelho 1992, Marini et al. 1992) assemelha-se àquela apresentada por granitos alcalinos do tipo $\mathrm{A}$, como, por exemplo, os granitos estaníferos fortemente diferenciados do Alaska (Newberry et al. 1990).

\section{AGRADECIMENTOS}

Ao Conselho Nacional de Desenvolvimento Científico e Tecnológico - CNPq - pela concessão de bolsa de estudos para a realização do Doutorado da autora, bem como pelo auxílio financeiro liberado para as análises laboratoriais; aos profissionais do SARM/CRPG - França, pelas análises químicas e pelas orientações, a Louis Raimbault, do Laboratório P. Sue - França, pelas análises de ETR em fluorita; à Prof ${ }^{\mathrm{a}} \mathrm{Dr}^{\mathrm{a}}$ Eleonora M. G. Vasconcellos, da Universidade Federal do Paraná UFPR, pela leitura criteriosa e pelas sugestões apresentadas; ao consultor do Boletim Paranaense de Geociências pelas críticas apresentadas ao texto. 


\section{REFERÊNCIAS}

ALDERTON D.H.M.; PEARCE J.A.; POTTS P.J. 1980. Rare earth element mobility during granite alteration: evidence from the southwest England. Earth Planet. Sci. Lett. 49: 149-165.

ALEKSANDROV I.V. 1977. Geochemistry of Li, Rb and $\mathrm{F}$ in granitoid process. Geochemistry International, 14:1-13.

ANDRADE G. F. de 1978As mineralizações de estanho, berilio e cobre do granito da Serra Branca, Cavalcante - Goiás. Universidade de Brasília, Dissertação de Mestrado, 83 p.

BAILEY J.C. 1977. Fluorine in granitic rocks and melts: a review. Chemical Geology, 19:1-42.

BAILEY S.W. 1984. Classification and structures of the micas. In: Micas, Review in Mineralogy, 13, Washington, Mineralogical Society of America, p. 1-12.

BAKER J.H. 1985. Rare earth and other trace element mobility accompanying albitization in a Proterozoic granite, W. Bergslagen, Sweden. Mineral. Mag., 49, 107-115.

BILAL E. 1991. Etude de deux massifs de la province stannifère de l' État de Goiás (Brésil) et des formations métasomatiques associés aux minéralisations $\mathrm{Sn}$ e Be. Thèse: St.-Etienne. $382 \mathrm{p}$.

BORODINA N.S.; FERSHTATER G.B. 1988. Composition and nature of muscovites in granites. International Geology Review, 30:375-381.

BOTELHO N.F. 1992. Les ensembles granitiques subalcalins a peralumineux minéralisés en Sn et In de la sous-province Paranã, Etat de Goiás, Brésil. Paris VI, Tese de Doutoramento. $344 \mathrm{p}$.

BOWDEN P.; KINNAIRD J.A; PIRAJNO F. 1990. Anorogenic granite evolution in Namibia - a fluid contribution. Geol. Journ., 25, 381-390.

BOWDEN P.; WHITLEY J.E. 1974. Rare-earth patterns in peralkaline and associated granites. Lithos, 7:15-21.

BREITER K.; SOKOLOVÁ M.; SOKOL A. 1991. Geochemical specialization of the tin-bearing granitoid massifs of NW Bohemia. Mineralium Deposita, 26:298-306.

CATHELINEAU M. 1987. U-Th-REE mobility during albitization and quartz dissolution in granitoids: evidence from south-east French Massif Central. Bull. Mineral, 110:249-259.

CHAROY B. 1979. Définition et importance des phénomènes deutériques et des fluides associés dans les granites. Conséquences métallogéniques. Tese de Doutoramento, INPL. 277 p.

CHAROY, B. 1986. The genesis of the Cornubian Batholith (South-West England): the example of the Carnmenellis pluton. Journ. Petrol. 27, 571-604.

COCHERIE, A. 1978. Géochimie des terres trares dasn les granitoïdes. Thèse $3{ }^{\text {ème }}$ Cycle. Rennes. 207 p.

COLLINS W.J.; BEAMS S.D.; WHITE A.J.R.; CHAPPEL B.W. 1982. Nature and origin of A-type granites with particular reference to southeastern Australia. Contr. Mineral. Petrol., 80:189-200

CONSTANTOPOULOS J. 1988. Fluid inclusions and rare earth elements geochemistry of fluorite from south-central Idaho. Econ. Geol., 83:626-636

CUNEY M.; STUSSI J.M.; MARIGNAC C. 1994. A geochemical comparison between West- and Central-European granites: implications for the origin of rare metal mineralization. In: Metallogeny of collisional orogens, Proceedings of the IAGOD Erzgebirge Meeting, Geyer June 4-6, Czech Geological Survey, Praha, 96-102.

DEBON F.; LE FORT P. 1983. A chemical-mineralogical classification of common plutonic rocks and associations. Trans. Roy. Soc. Soc. Edinb-Earth Sci., 73:135-149.

DEBON F.; LE FORT P. 1988. A cationic classification of common plutonic rocks and their magmatic associations : principles, method, application. Bull. Mineral., 111:493-510.

EBY G.N. 1990. The A-type granitoids: a review of their occurence and chemical characteristics and speculations on their petrogenesis. Litho. 26:115-134.

EVENSEN N.M.; HAMILTON P.J.; O'NIONS R.K. 1978. Rareearth abundances in chondritic meteorites. Geochim Cosmochim. Acta, 42:1199-1212.

FOURCADE, S. 1981. Géochimie des granitoïdes. Université Paris - 7. Tese de Doutoramento. $189 \mathrm{p}$.

FOWLER A.D.; DOIG R. 1983. The significance of europium anomalies in the REE spectra of granites and pegmatites, Mont Laurier, Quebec. Geochim. Cosmochim. Acta, 47:11311137.

HALL A. 1971. Greisenization in the granite of Cligga Head, Cornwall. Proc. Geol. Assoc. 82:209-230.

HANSON G.N. 1978. The application of trace elements to the petrogenesis of igneous rocks of granitic composition. Earth Planet. Sci. Lett., 38: 26-43.

HALTER W.E.; WILLIAM-JONES A.E.; KONTAK D.J. 1996. The role of greisenization in cassiterite precipitation of the East-Kemptville tin deposit, Nova Scotia. Econ. Geol., 91:368385.

HERMANN A.G. 1978. Yttrium and Lanthanides. In: WEDEPOHL K.H. (ed.) Handbook of geocheminstry, Springer Verlag: Berlin, II-5, 39: 57-71.

KOLJONEN T.; ROSENBERG R.J. 1974. Rare earth elements in granitic rocks. Lithos, 7:249-261.

LEROY J.-L.; TURPIN L. 1988. REE, Th and U behaviour and supergene processes in a granitic environment. Chem. Geol., 68:239-251

MARINI O.J.; BOTELHO N.F. 1986. A Província Estanífera de Goiás. Revista Brasileira de Geociências, 16:119-131.

MARINI O.J.; BOTELHO N.F.; ROSSI P. 1992. Elementos ter- 
PINTO-COELHO, C. V. Comportamento geoquímico dos elementos terras raras...

ras raras em granitóides da Província Estanífera de Goiás. Revista Brasileira de Geociências, 22: 8-19.

McCARTHY T.S.; KABLE E.J.D. 1978. On the behaviour of rare-earth elements during partial melting of granitic rock. Chem. Geol. 22:21-29.

MICHARD A., ALBAREDE F. 1986. The REE content of some hydrothermal fluids. Chem. Geol., 55:51-60.

MILLER C. F.; STODDARD E.F.; BRADFISH L.J.; DOLLASE W. A. 1981. Composition of plutonic muscovite: genetic implications. Canadian Mineralogist, 19:25-34.

MÖLLER P.; MUECKE G.K. 1984. Significance of europium anomalies in silicate melts and crystal-melt equilibria: a reevaluation. Contr. Mineral. Petrol., 87:242-250.

MÖLLER P.; PAREKH P.P.; SCHNEIDER H.J. 1976. The application of $\mathrm{Tb} / \mathrm{Ca}-\mathrm{Tb} / \mathrm{La}$ abundance ratios to problems of fluorspar gênesis. Mineral. Deposita, 11:111-116.

MORTEANI G.; MÖLLER P.; HOEFS J. 1986. Rare-earth element and oxygen isotope studies of altered variscan granites; the western Harz (Germany) and southern Sardinia (Italy). Chem. Geol. 54: 53-68.

NAGASAWA H.; SCHNETZLER C.C. 1971. Partitioning of rare earth, alkali and alkaline earth elements between phenocrysts and acidic igneous magma. Geochim. Cosmochim. Acta, 35:953-968.

NEWBERRY R.J.; BURNS L.E.; SWANSON S.E.; SMITH T.E. 1990. Comparative petrologic evolution of the $S n$ and $W$ granites of the Fairbanks-Circle area, interior Alaska. Geol. Soc. Am. Spec. Paper, 246:121-142.

PEARCE J.A.; HARRIS N.B.W.; TINDLE A.G. 1984. Trace element discrimination diagrams for the tectonic interpretation of granitic rocks. Journ. Petrol., 25:956-983.

PINTO-COELHO C. 1996. Evolution magmatique et hydrothermale du Massif granitique de Serra Branca - Etat de Goiás - Brésil: définition des processus d'altération postmagmatique en liaison avec les minéralisations en $\mathrm{Sn}$, Be et F. INPL, Tese de Doutoramento. $271 \mathrm{p}$.

PINTO-COELHO C.; BOTELHO N.F.; ROGER G. 1999. Mobilité des terres rares au cours des altérations hydrothermales: l'exemple du granite de Serra Branca-Brésil Central. C.R. Acad. Sci. Paris 328:663-670.

PINTO-COELHO C.; CHAROY B. 2001 Cronologia das alterações pós-magmáticas associadas ao Maciço Granítico da Serra Branca - Goiás. Revista Brasileira de Geociências, 31(1):1-6.

PLIMER I.R. 1987. Fundamental parameters for the formation of granite-related tin deposits. Geol. Rundsch. 76:23-40.

PLIMER I.R.; LU, J.; KLEEMAN, J.D. 1991. Trace and rare earth elements in cassiterite-sources of components for the tin deposits of the Mole Granite, Austrália. Mineral. Deposita, 26:267-274.

SPEER J.A. 1984. Micas in igneous rocks. In Micas, Review in Mineralogy, 13, Washington, Mineralogical Society of America, p. 299-356.

STRECKEISEN A. 1976. To each plutonic rock its proper name. Earth Sci. Rev., 12:1-33.

TAYLOR R.P.; FRYER B.J. 1983. Rare-earth lithogeochemistry of granitoid mineral deposits. CIM Bull., 76:74-84.

TEIXEIRA L.M. 1998. Caracterização dos minerais portadores de terras raras em granitos da Sub-província Estanífera Paraná-Goiás. Universidade de Brasília. 223 p Dissertação de Mestrado.

TINDLE A.G.; PEARCE J.A. 1981. Petrogenetic modelling of in-situ fractional crystallization in the zoned Loch Doon Pluton, Scotland. Contr. Mineral. Petrol., 78:196-207.

VANSHTEYN, B.G.; MARIN, Y.B.; SBUBLOV, G.T. 1979. Studies of petrochemical evolution in age series of granitoid formations (as in Kazakhstan). Int. Geol. Rev. 23:683-694.

WALEN J.B.; CURRIE K.L.; CHAPPELL B.W. 1987. A-type granites: geochemical characteristics, discrimination and petrogenesis. Contr. Mineral. Petrol., 95:407-419.

WARD C.D.; MCARTHUR J.M.; WALSH J.N. 1992. Rare earth element behaviour during evolution and alteration of the Dartmoor granite, SW England. Journ. Petrol., 33:785-815.

WHITFORD D.J., KORSCH M.J.; PORRITT P.M.; CRAVEN S.J. 1988. Rare earth element mobility around the volcanogenic polymetallic massive sulfide deposit at Que River, Tasmânia, Austrália. Chem. Geol., 68:105-119.

Recebido em 24 set. 2004 Aceito em 11 ago. 2005 